\title{
Avaliação do potencial da lagoa de estabilização do Aterro Sanitário do Município de Puxinanã-PB, Nordeste do Brasil
}

\author{
Natália de Souza Guedes, Bárbara Freire de Oliveira, Guilherme de \\ Andrade Carvalho, José Marcelino de Lima Silva, João Carlos de \\ Miranda e Silva*
}

Superintendência de Administração do Meio Ambiente (SUDEMA). Coordenadoria de Medições Ambientais. Av. Monsenhor Walfredo Leal, 181. Tambiá, João Pessoa-PB (CEP 58020-540).*E-mail: jota13@gmail.com.

Resumo. Atualmente, o destino dos resíduos sólidos produzidos diariamente nas cidades, tem sido motivo de discussão em diversas instâncias governamentais. Para tratar de tal situação, hoje em dia, aterros sanitários se tornaram o meio mais utilizado, de menor custo e mais adequado ambientalmente para a estocagem desses resíduos. Porém, nos aterros ocorre a geração de chorume (líquido negro e mal cheiroso), este chorume por ser altamente poluidor precisa ser tratado adequadamente. Desta forma, este trabalho teve por objetivo estudar o potencial da lagoa de estabilização do aterro sanitário de Puxinanã, município da região metropolitana de Campina Grande-PB, que se encontra inativo no momento, para o tratamento do chorume. Para a análise foram realizadas coletas de amostras na entrada e na lagoa de estabilização para fins de análises físico, química, bacteriológica e de metais pesados. Com o resultado das análises, verifica-se que há potencial da lagoa de estabilização, que continua operando e tratando o lixiviado, porém com uma baixa eficiência para redução da carga orgânica, eficiência de remoção igual a 36,1\%. Portanto, pode-se concluir assim que há necessidade de melhoramentos na técnica utilizada para o tratamento do lixiviado (chorume) do aterro.

Palavras-chave: Aterro Sanitário, Chorume, Lagoa de Estabilização.

Abstract. Potential evaluation of stabilization pond landfill of the Municipallity of Puxinanã-PB, Northeast Brazil. Currently, the disposal of solid waste produced daily in the cities, has been the subject of discussion in various government bodies. To address this situation, today, landfill sites have become the most widely used means, less costly and more environmentally suitable for storage of such wastes. However, in landfills is the generation of leachate (black and smelly liquid), this slurry to be highly pollutant needs to be handled properly. Thus, this study aimed to study the potential of pond's stabilization of the Landfill Puxinanã, the metropolitan Region of Campina Grande-PB, which is currently inactive, for the treatment of landfill leachates. For the analysis samples were collected at the inlet and lagoon stabilization for purposes of physical and chemical analysis, bacteriological and heavy metal. With the test results, it appears that there is potential stabilization pond, which continues operating and treating the leachate, though with low efficiency to reduce the organic load removal efficiency of $36.1 \%$. Therefore, it
Recebido: 10/12/2015

Aceito: 28/12/2015

Publicado: 31/12/2015

Acesso Aberto Artigo completo

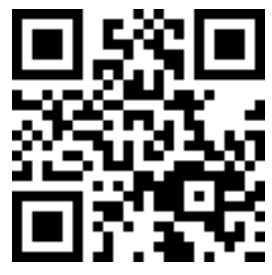


can be concluded that there is thus a need for improvements in the technique for treating the leachate (slurry) from the landfill.

Keywords: Landfill, Leachate, Pond's stabilization.

\section{Introdução}

O recebimento do lixo urbano nos lixões ou aterros a céu aberto foi um procedimento utilizado durante muitos anos por diversos países. Neste tempo não havia qualquer preocupação com a técnica da disposição do lixo em uma determinada área previamente escolhida (CETESB, 1995).

Em 2010, foi promulgada a Lei $n^{\circ}$ 12.305/2010 que instituiu a Política Nacional de Resíduos Sólidos (PNRS), proibindo a disposição de resíduos sólidos a céu aberto (lixão). Segunda esta lei, a partir de 2014, todos os municípios deverão implementar uma disposição ambientalmente adequada para seus resíduos sólidos urbanos. Diante de tal fato, a implementação de aterros sanitários surge como protagonista na busca da resolução dos problemas gerados pela má disposição dos resíduos (Santos, 2014).

Nos aterros sanitários, o método se dá por meio do depósito dos resíduos em células no solo. Esses depósitos são constituídos em camadas de resíduos intercaladas com material inerte, geralmente de solo. As células possuem sua base e laterais devidamente impermeabilizadas com mantas de polietileno de alta densidade ou com argila compactada. Quando saturadas, as células são cobertas, utilizando solo (Fieira, 2014).

Contudo, em função da degradação biológica dos resíduos, somado à infiltração de águas de chuva e à umidade natural dos resíduos aterrados, existe a formação dos efluentes líquidos dos aterros, conhecidos como chorume ou lixiviado. Este efluente apresenta aspecto escuro e turvo, com odores desagradáveis, possuindo em sua composição altos teores de substâncias orgânicas e inorgânicas (Silva, 2002).

O chorume, por possuir caráter altamente tóxico, deve ser submetido a tratamentos adequados antes de ser lançado ao ambiente ou a redes coletoras de esgoto.
Dentre os métodos mais utilizados destacam-se o tratamento biológico, a recirculação através do aterro sanitário e o tratamento físico e químico (Nakamura, 2012).

O tratamento biológico consiste na degradação da matéria orgânica e de compostos de difícil degradação por microrganismos, na ausência ou presença de oxigênio. Diferentes tratamentos biológicos podem ser aplicados ao chorume dos aterros, destacando-se as lagoas de estabilização e o sistema de lodos ativados (CEMPRE, 2010).

Os sistemas de lagoas de estabilização constituem um processo biológico de tratamento de chorume que se caracterizam pela simplicidade, eficiência e baixo custo, em que a estabilização da matéria orgânica é realizada pela oxidação bacteriológica (oxidação aeróbia ou fermentação anaeróbia) e/ou redução fotossintética das algas. No Brasil, devido às condições climáticas favoráveis e disponibilidade de territórios, as lagoas são utilizadas em larga escala, tendo-se observado boa eficiência quanto à qualidade do efluente tratado (Martins et al., 2010).

Diante do exposto, o presente trabalho visa a avaliar o potencial da lagoa de estabilização no tratamento do chorume do Aterro Sanitário de Puxinanã/PB. Apesar de o aterro estar interditado desde julho de 2015 e não receber mais resíduos, a quantidade de chorume produzido ainda é significativa, justificando a necessidade do contínuo funcionamento da lagoa.

\section{Objetivos}

\section{Objetivo geral}

Este trabalho tem como objetivo estudar 0 potencial do sistema de tratamento do chorume produzido no aterro sanitário de Puxinanã/PB que no momento encontra-se desativado. 


\section{Objetivos específicos}

- Caracterizar o chorume produzido no aterro, quanto aos parâmetros cor, turbidez, $\mathrm{pH}$, condutividade elétrica, sólidos dissolvidos totais, salinidade, DBO, DQO, coliformes termotolerantes, alcalinidade total, cloretos, nitrito, nitrato, dureza total, ferro dissolvido, sulfatos, fosfatos e manganês total.

- Caracterizar o lixiviado produzido no aterro, após o tratamento, quanto aos parâmetros anteriormente citados.

- Verificar a eficiência de remoção de DBO do sistema de tratamento.

\section{Material e métodos}

\section{Descrição da região em estudo}

O aterro sanitário a ser estudado está localizado no município de Puxinanã, que está inserido na Microrregião de Campina Grande e na Mesorregião do Agreste Paraibano. Sua população em 2015 foi estimada pelo Instituto Brasileiro de Geografia e Estatística (IBGE, 2010) em 13.557 habitantes, distribuídos em $73 \mathrm{~km}^{2}$ de área.
Este aterro recebia resíduos sólidos produzidos nas cidades de Campina Grande, Puxinanã e Montadas e em mais 10 empresas privadas, recebendo em média, 400.000 t/mês de resíduos. Porém, em 6 de julho de 2015, a Prefeitura Municipal de Puxinanã decidiu interditar o aterro após serem detectadas diversas irregularidades.

Hoje, o aterro continua interditado, mas a produção de chorume continua significativa, exigindo sua contínua drenagem e tratamento. O tratamento do lixiviado no aterro é feito por meio de uma lagoa de estabilização.

\section{Coleta das amostras}

Para verificação da eficiência da lagoa de estabilização, foram realizadas cinco coletas locais no aterro sanitário de Puxinanã (Figura 1).

A primeira coleta foi realizada na entrada da lagoa de estabilização, a fim de caracterizar o chorume produzido no aterro (Figura 2).

As demais coletas foram realizadas em quatro pontos distintos da lagoa de estabilização (P1, P2, P3 E P4), com o objetivo de se obter uma amostra composta, ou seja, uma amostra oriunda da mistura de várias alíquotas, visando minimizar os efeitos da variabilidade (Figura 3).

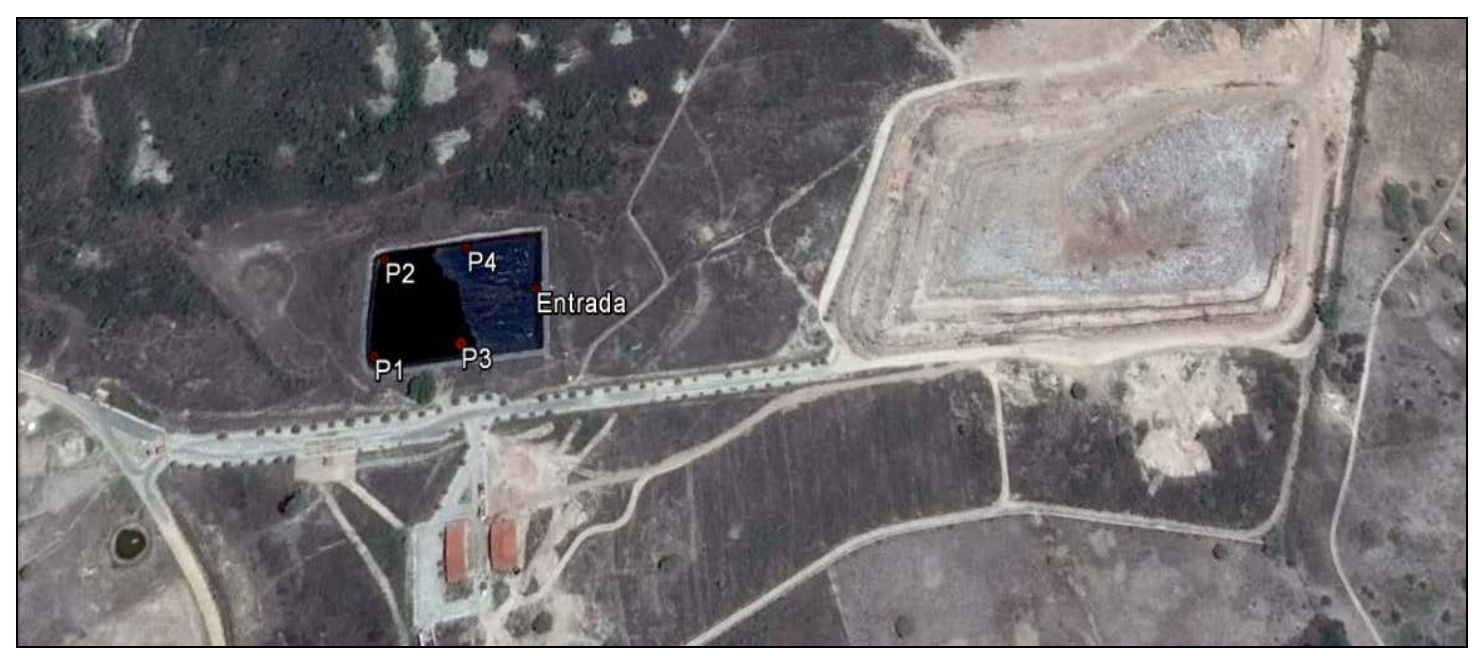

Figura 1. Localização dos pontos de coleta. 


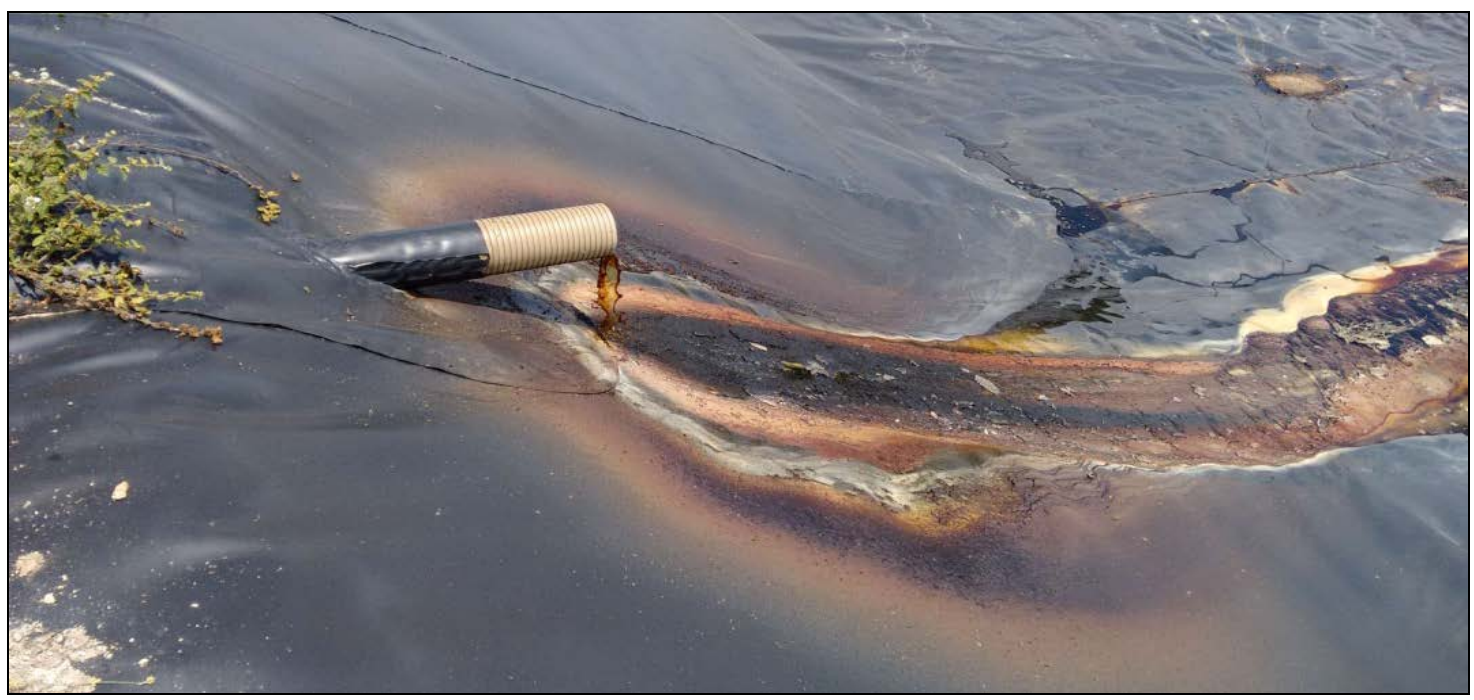

Figura 2. Entrada do chorume na lagoa de estabilização.

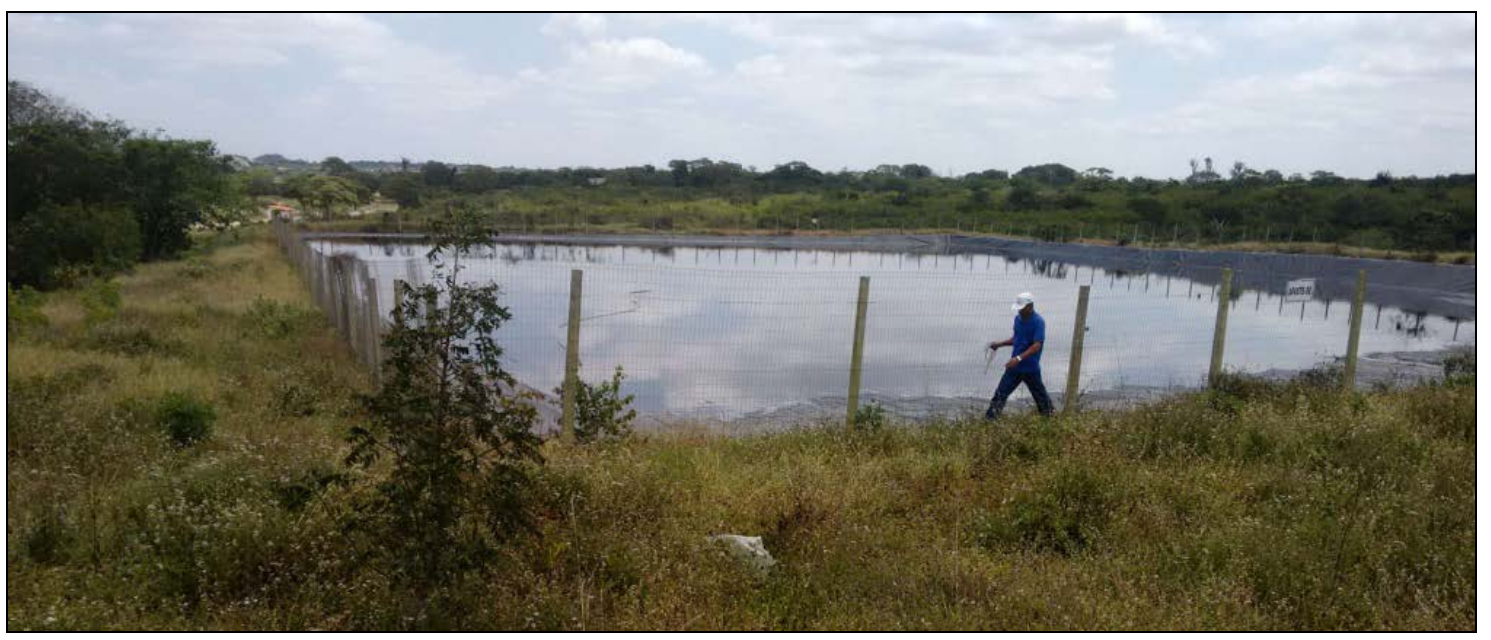

Figura 3. Coleta realizada em quatro pontos estratégicos da lagoa de estabilização.

Ainda no local, foram feitas algumas anotações a cerca das coletas, para verificar possíveis variações nas análises em decorrência da hora e da temperatura em que se encontrava o ambiente, além do oxigênio dissolvido, $\mathrm{pH}$ e temperatura das amostras.

\section{Análise das amostras}

Após as coletas, as amostras foram mantidas em recipientes hermeticamente fechados e levados para análise na Coordenadoria de Medições Ambientais da, Superintendência de Administração do Meio Ambiente (SUDEMA), localizada no
Município de João Pessoa, Estado da Paraíba.

As variáveis que foram avaliadas para o Aterro Sanitário, foram: Demanda Bioquímica de Oxigênio (DBO), Demanda Química de Oxigênio (DQO), pH, cor, turbidez, condutividade elétrica, sólidos dissolvidos totais, salinidade, dureza total, cloretos, alcalinidade total, nitrito, nitrato, ferro dissolvido, sulfato, fosfato, manganês total, além de coliformes termotolerantes. Os quais foram determinados de acordo com as metodologias descritas no Standard Methods for the Examination of Water and 
Wastewater (Eaton et al., 1995), CETESB (2015) e FEEMA (1993).

Após a realização da caracterização do chorume antes e após o tratamento na lagoa de estabilização, foi calculada a eficiência de remoção de DBO utilizandose a equação de eficiência geral (Equação 1) (Von Sperling, 2002):

$$
E=\frac{C o-C e}{C o} \times 100
$$

Onde:

$\mathrm{E}=$ Eficiência de remoção (\%);

efluente bruto;

$$
\text { Co = valor do parâmetro no }
$$

efluente tratado.

$$
\mathrm{Ce}=\text { valor do parâmetro no }
$$

Por fim, compararam-se os resultados com os parâmetros estabelecidos na Resolução CONAMA $n^{\circ} \quad 430 / 2011$ (Brasil, 2011), que normatiza o lançamento de efluentes nos recursos hídricos.

\section{Resultados e discussão}

A Tabela 1 apresenta a caracterização do chorume na entrada da lagoa de estabilização.

Os resultados obtidos demonstram que o chorume em questão apresenta uma Demanda Bioquímica de Oxigênio relativamente mais baixa que a demanda química de oxigênio, a qual se encontra significativamente alta. De acordo com Jardim e Canela (2004), para um dado efluente, se a relação DQO/DBO $<2,5$ ele é facilmente biodegradável. Se a relação
$5,0<\mathrm{DQO} / \mathrm{DBO} \geq 2,5$ o efluente irá exigir cuidados na escolha do processo biológico para que se tenha uma remoção desejável de carga orgânica, e se DQO/DBO $>5$, então o processo biológico tem muito pouca chance de sucesso, e a oxidação química aparece como um processo alternativo. A partir dos resultados obtidos pode-se encontrar uma relação DQO/DBO de aproximadamente 21 , o que significa que a oxidação química seria mais indicada para o tratamento do chorume do Aterro de Puxinanã.

Em relação aos metais no lixiviado, foi verificado altos teores de concentração de manganês total, que pode ser explicado em relação aos resíduos sólidos que são destinados ao aterro sanitário e em relação ao seu controle no processo de separação, por classificação.

Na Tabela 2, são apresentados os resultados da caracterização do chorume após o tratamento, por processo biológico, na lagoa de estabilização.

A partir dos dados obtidos verificase que o pH de lançamento ao meio que ficou em torno de 8,3, encontra-se dentro dos limites máximos permitidos pela Resolução CONAMA no 430/2011, que é de 5 a 9 (Brasil, 2011). Com relação à temperatura a resolução determina que seja inferior a $40^{\circ} \mathrm{C}$, portanto o chorume tratado apresenta uma temperatura dentro dos limites estabelecidos, uma vez que o valor encontrado foi de $31^{\circ} \mathrm{C}$.

No que diz respeito aos metais, verifica-se que a concentração de ferro dissolvido de 10,55mg/L Fe está dentro dos

Tabela 1. Característica chorume produzido no aterro.

\begin{tabular}{ll}
\hline Estação de Amostragem & Entrada \\
\hline Data da Coleta & $08 / 09 / 2015$ \\
Hora da Coleta & $11: 40$ \\
Tipo de Amostra & Instantânea \\
Temperatura Ambiente $\left({ }^{\circ} \mathrm{C}\right)$ & 32 \\
Temperatura da Amostra $\left({ }^{\circ} \mathrm{C}\right)$ & 31 \\
Cor (mg/L Ptcor) & 359 \\
Turbidez (UNT) & 303 \\
pH & 8,29 \\
Condutividade Elétrica $\left(\mu S \mathrm{~cm}^{-1}\right)$ & 34900
\end{tabular}

Rev. Bras. Gest. Amb. Sustent., 2015, v. 2, n. 3, p.129-136. 
Tabela 1. Continuação.

\begin{tabular}{ll}
\hline Estação de Amostragem & Entrada \\
\hline Sólidos Dissolvidos Totais (mg/L) & 28269 \\
Salinidade (ppt) & 22,4 \\
Oxigênio Dissolvido (mg/L) & 0 \\
DBO $_{\text {5dias }}(\mathrm{mg} / \mathrm{L})$ & 360 \\
DQO (mg/L) & 7864 \\
Coliforme Termotolerantes UFC/100 mL & 430 \\
Alcalinidade Total (mg/L) & 12900 \\
Cloretos (mg/L) & 8722 \\
Nitrito & 1,7 \\
Nitrato & 54 \\
Dureza Total (mg/L CaCo $)$ & 2000 \\
Ferro Dissolvido (mg/L Fe) & 9,25 \\
Sulfatos (mg/L SO 4$)$ & 300 \\
Fosfatos & 56 \\
Manganês Total(mg/L Mn) & 47,5 \\
\hline
\end{tabular}

Tabela 2. Resultados das análises após processo biológico na lagoa de estabilização.

\begin{tabular}{|c|c|}
\hline Estação de Amostragem & Lagoa de estabilização \\
\hline Data da Coleta & $08 / 09 / 2015$ \\
\hline Hora da Coleta & Aprox. 12:00 \\
\hline Tipo de Amostra & Composta de 4 amostras \\
\hline Temperatura Ambiente $\left({ }^{\circ} \mathrm{C}\right)$ & 32 \\
\hline Temperatura da Amostra $\left({ }^{\circ} \mathrm{C}\right)$ & 31 \\
\hline Cor (mg/L Ptcor) & 164 \\
\hline Turbidez (UNT) & 307 \\
\hline $\mathrm{pH}$ & 8,27 \\
\hline Condutividade Elétrica $\left(\mu S \mathrm{~cm}^{-1}\right)$ & 31900 \\
\hline Sólidos Dissolvidos Totais (mg/L) & 25839 \\
\hline Salinidade (ppt) & 20 \\
\hline Oxigênio Dissolvido (mg/L) & 0 \\
\hline $\mathrm{DBO}(\mathrm{mg} / \mathrm{L})$ & 230 \\
\hline $\mathrm{DQO}(\mathrm{mg} / \mathrm{L})$ & 8847 \\
\hline Coliforme Termotolerantes UFC/100 mL & 310 \\
\hline Alcalinidade Total (mg/L) & 6400 \\
\hline Cloretos (mg/L) & 6811 \\
\hline Nitrito & 2,1 \\
\hline Nitrato & 92,5 \\
\hline Dureza Total (mg/L CaCo $\left.{ }_{3}\right)$ & 2280 \\
\hline Ferro Dissolvido (mg/L Fe) & 10,45 \\
\hline Sulfatos $\left(\mathrm{mg} / \mathrm{L} \mathrm{SO}_{4}\right)$ & 160 \\
\hline Fosfatos & 10,55 \\
\hline Manganês Total (mg/L Mn) & 68,5 \\
\hline
\end{tabular}

padrões da resolução que determina que a concentração seja inferior a $15 \mathrm{mg} / \mathrm{L}$.Fe.

A média de remoção de DBO obtida no sistema de tratamento foi de 36,1\%, essa eficiência de remoção é considerada significativamente baixa,uma vez que a Resolução CONAMA $n^{\circ}$ 430/2011 determina uma remoção mínima de 60\%, verificando assim uma eficiência não desejada no tratamento do chorume do aterro em estudo.

Lima (2006) estudou o desempenho de remoção de poluentes de lixiviados pelo sistema de tratamento do Aterro Sanitário de Betim-MG e obteve as seguintes eficiências médias de remoção: $76 \%$ de 
DBO, 84\% de DQO e entre os metais pesados, o ferro e o cádmio foram os que apresentaram maior eficiência sendo elas, $87 \%$ e $71 \%$, respectivamente.

Segundo Lins et al. (2005), para obter um bom desempenho no tratamento de lixiviados por lagoas de estabilização, devese atentar para algumas variáveis que possivelmente tenham interferido na mesma. São elas:

- Tempo de detenção hidráulica suficiente: tempo mínimo necessário ao desenvolvimento de microrganismo em um dado ambiente, está diretamente ligado a vazão do chorume na lagoa de estabilização.

- Vazão do chorume: quanto menor a vazão do afluente, maior será o tempo de detenção hidráulica de uma lagoa. A vazão ainda poderá afetar a eficácia do sistema, onde o seu aumento ou diminuição excessiva, uma vez que irá alterar na quantidade de nutrientes, oxigênio, $\mathrm{pH}$ e temperatura do meio.

- Uma relação DQO/DBO elevada: consequentemente a maior parte da matéria orgânica não será biodegradável.

- Baixos teores de cor e turbidez: quando há uma elevação da mesma, teremos como consequência uma redução da luz no meio, desta forma inibindo processos metabólicos.

\section{Conclusão}

Os valores encontrados na verificação do potencial da lagoa de estabilização confirmam que, mesmo o aterro sanitário inativo, a lagoa de estabilização continua operando e tratando o lixiviado, porém este tratamento encontrase bastante ineficiente.

A lagoa de estabilização possui uma baixa eficiência na remoção da matéria orgânica com um valor de remoção igual a $36,1 \%$.
Possíveis influências nos valores obtidos podem ter sido através da temperatura em que se encontrava $o$ chorume (onde irá influenciar diretamente no crescimento do microrganismo), as coletas foram realizadas em época de estiagem e desta forma a vazão do afluente pode ter sido consideravelmente baixa e havendo a necessidade de maior tempo de detenção hidráulica.

A verificação do potencial da lagoa de estabilização só confirma através dos dados que há necessidade de melhoramento na técnica utilizada para o tratamento do lixiviado (chorume), no Aterro Sanitário de Puxinanã, para seu possível descarte dentro dos limites estabelecidos pela Resolução CONAMA nº 430/2011 (Brasil, 2011).

\section{Declaração de conflito de interesses}

Os autores declaram não haver conflitos de interesses.

\section{Referências}

Brasil. Leis, decretos etc. Lei ${ }^{0}$ 12.305, de 2 de agosto de 2010. Institui a Política Nacional de Resíduos Sólidos; altera a Lei no 9.605, de 12 de fevereiro de 1998; e dá outras providências. Disponível em: <http://www.planalto.gov.br/ ccivil_03/_ato2007-2010/2010/lei/112305.htm>. Acesso em: 14 nov. 2015.

Brasil. Leis, decretos etc. Resolução

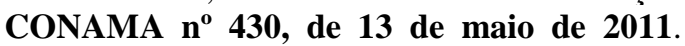
Dispõe sobre as condições de lançamento de efluentes, complementa e altera a Resolução $\mathrm{n}^{\circ}$ 357, de 17 de março de 2005, do Conselho Nacional do Meio Ambiente - CONAMA. Disponível em: <http://www.mma.gov.br/ port/conama/legiabre.cfm?codlegi=646>.

Acesso em: 14 nov. 2015.

CEMPRE. Manual de gerenciamento integrado. 3 ed. São Paulo: CEMPRE, 2010.

CETESB. Companhia Ambiental do Estado de São Paulo. Licenciamento Ambiental. Resolução SMA ñ 46, de setembro de 1995. São Paulo: Governo do Estado.

CETESB. Norma Técnica $\mathbf{n}^{0} \mathbf{L} 5.214$, de 30 de agosto de 2007. Coliformes totais determinação pela técnica de membrana filtrante. Disponível em: $<$ http://www.cetesb.sp.gov.br/wp- 
content/uploads/sites/11/2013/11/DD_203_DO. pdf $>$. Acesso em: 21 set. 2015.

Eaton, A. D.; Clesceri, L. S.; Rice, E. W.; Greenberg, A. E.; Franson, M. A. H. (Ed.). Standard methods for the examination of water and wastewater. 21. ed. Washington, D.C.: American Public Health Association, 2005.

FEEMA - Fundação Estadual de Engenharia do Meio Ambiente. Manual Métodos FEEMA. Rio de Janeiro: FEEMA, 1983.

Fieira, C. Avaliação da eficiência das lagoas de tratamento do Aterro Municipal de Francisco Beltrão. Francisco Beltrão: Universidade Tecnológica Federal do Paraná, 2014. (Trabalho de Conclusão de Curso de Engenharia Ambiental). Disponível em: $<$ http://repositorio.roca.utfpr.edu.br/jspui/ bitstream/1/2079/1/FB_COEAM_2013_2_07. pdf $>$. Acesso em: 14 nov. 2015.

IBGE - Instituto Brasileiro de Geografia e Estatística. Indicadores de Desenvolvimento Sustentável: Brasil 2010. Brasília, 2010. Disponível em: <http://cidades.ibge.gov.br/ xtras/perfil.php?lang=\&codmun $=251240 \&$ search=paraiba|puxinana $>$. Acesso em: 14 nov. 2015.

Jardim, W. F.; Canela, M. C. Fundamentos da oxidação química no tratamento de efluentes e remediação de solos. Campinas: UNICAMP, 2004.

Lima, W. S. Avaliação do desempenho de remoção de poluentes de lixiviados: um estudo de caso para o sistema de tratamento do Aterro Municipal de Betim - Minas Gerais. Belo Horizonte: Universidade Federal de Minas Gerais, 2006. (Dissertação de mestrado em Saneamento, Meio Ambiente e Recursos Hídricos).
Lins, E. A. M.; Lins, M. C. M.; Lima, M. A. G. A.; Araújo, J. M.; Jucá, J. F. T. Monitoramento de lagoas de estabilização no tratamento de chorume - Aterro da Muribeca. Anais do XXIII Congresso Brasileiro de Engenharia Sanitária e Ambiental, Campo Grande, 2005.

Martins, C. L.; Castilhos Júnior, A. B.; Costa, R. H. R. Desempenho de sistema de tratamento de lixiviado de aterro sanitário com recirculação do efluente. Revista de Engenharia Sanitária e Ambiental, v. 15, p. 401-410, 2010.

Nakamura, C. Y. Estudo de um sistema de lagoas de estabilização no tratamento do lixiviado e da água subterrânea no entorno de aterros sanitários em Minas Gerais. Viçosa: Universidade Federal de Viçosa, 2012. (Dissertação de Pós-Graduação em Engenharia Civil).

Santos, J. V. Levantamento do sistema de limpeza urbana no Município de PuxinanãPB: um estudo com enfoque populacional e administrativo. Campina Grande: Universidade Estadual da Paraíba, 2014. (Trabalho de Conclusão de Curso de Graduação em Geografia).

Silva, A. C. Tratamento do percolado de aterro sanitário e avaliação da toxicidade do efluente bruto e tratado. Rio de Janeiro: Universidade Federal do Rio de Janeiro, 2002. (Dissertação de Mestrado em Engenharia Civil). Von Sperling, M. Lagoas de estabilização. Belo Horizonte: Universidade Federal de Minas Gerais, 2002.

Informação da Licença: Este é um artigo Open Access distribuído sob os termos da Licença Creative Commons Attribution, que permite uso irrestrito, distribuição e reprodução em qualquer meio, desde que a obra original seja devidamente citada. 